\title{
La paternidad desde el punto de vista relacional. Sobre el "nacimiento del padre"1
}

\author{
Alejandro Ávila Espada ${ }^{a}$ \\ IPR, UCM, Madrid
}

\begin{abstract}
El "nacimiento del padre" es una construcción relacional derivada de la experiencia de la matriz relacional en la que se ha sido hijo/a, se ha vivido con padres reales, simbólicos e imaginarios, y se ha construido una fantasía identificatoria con los diferentes padres posibles: Desde el padre narcisista que busca objeto para su gratificación narcisista en el hijo/a, el padre maternal que se realiza en la mater-paternidad; y el padre capaz de serlo sin invadir el espacio de la maternidad pero sosteniéndolo, y a la vez transformando su narcisismo en creatividad, aceptación de los límites y sabiduría. Usamos capacidades de "materno/paterno-parentalidad" que se han construido sobre la base de 1) La experiencia vivida con los propios padres y abuelos; 2) La experiencia vivida de la relación de los padres con sus padres; y 3) La transmisión transgeneracional que ellos portan. La perspectiva relacional nos da una oportunidad de pensar la matriz relacional en la que la parentalidad se teje, disfuncional o saludablemente.
\end{abstract}

Palabras clave: Parentalidad, Paternidad, Maternidad.

The "birth of the father" is a relational construction derived from the experience of the relational matrix in which one has been a son/daughter, one has lived with real, symbolic and imaginary parents, and an identifying fantasy has been constructed with the different possible parents: From the narcissistic father who seeks an object for his narcissistic gratification in the son / daughter, the maternal father who performs in the motherfatherhood; and the father capable of being without invading the space of motherhood but sustaining it, and at the same time transforming his narcissism into creativity, acceptance of limits and wisdom. We use "maternal / paternal-parenting" abilities that have been built on the basis of 1) The experience lived with one's parents and grandparents; 2 ) The lived experience of the parents' relationship with their parents; and 3) The transgenerational transmission they carry. The relational perspective gives us an opportunity to think about the relational matrix in which parenthood is woven, dysfunctionally or healthily.

Key Words: Parenthood, Fatherhood, Motherhood.

English Title: Faherhood from the relational point of view. On the "birth of the father"

\section{Cita bibliográfica / Reference citation:}

Ávila Espada, A. (2019). La paternidad desde el punto de vista relacional. Sobre el "nacimiento del padre". Clínica e Investigación Relacional, 13 (1): 148-169. [ISSN 1988-2939] [Recuperado de www.ceir.info ] DOI: 10.21110/19882939.2019.130111

\footnotetext{
${ }^{1}$ Texto revisado de la conferencia pronunciada en Lisboa, en las II Jornadas de PSIRelacional-Associaçao de Psicoanálise Relacional: O Nascimento da Mae, Facultad de Psicología, Univ. de Lisboa, 17-19 de Mayo de 2018. (C) de este texto, Alejandro Ávila Espada.

CelR Vol. 13 (1) - Abril 2019 ISSN 1988-2939 - www.ceir.info

(c) Derechos reservados/Copyright de Clínica e investigación Relacional y los autores. Prohibida la reproducción total o parcial sin autorización expresa. Este material es para uso científico y profesional exclusivamente y puede contener información clínica sensible. Los editores no se responsabilizan de los contenidos de los autores. Dirigir las consultas sobre derechos y autorizaciones a ceir@psicoterapiarelacional.es
} 
A mis hijos, que conocen mis carencias como padre.

A mi padre, quien, desde la ausencia, proyectó en mí su sombra de constructor.

\section{Recuperando al padre idolizado, pero relegado en el psicoanálisis}

A pesar de su supuesta importancia, la figura y función del padre ha recibido notoriamente menos atención que la madre en la literatura psicoanalítica (de los 883 trabajos incluidos en la base documental PEP hasta 2017, cuyo título incluye el término padre o madre, algo más del doble se dedican a la madre [68\%] que al padre [32\%]). Más allá de la tendencia que marca esta estadística, y en el contexto del predominante interés que suscita la figura y función materna, nos vamos a ocupar de considerar la singularidad del padre, su papel en el desarrollo del niño y la niña, así como intentar una mejor comprensión de algunas de sus funciones singulares, y de los procesos que hacen posible o interfieren en que sean desplegadas y ejercidas en el contexto de la parentalidad en la sociedad contemporánea, resultante de tradiciones y tendencias de cambio. Las fuentes en que nos basaremos son la experiencia clínica y personal, los informes de casos en tratamiento, las propuestas teóricas formuladas, y las evidencias aportadas por la no muy abundante investigación.

Con Sigmund Freud $(1900,1913)$ el padre es situado en una posición central en el origen, regulación y resolución del complejo de Edipo, cuya principal función es romper la idílica unión con la madre, abriéndole así al hijo el mundo, junto a valorar y tolerar las diferencias sexuales, y catalizando en torno a la figura paterna el temor del niño ante la autoridad del padre $^{b}$, que Freud conceptualizará más tarde como la herencia filogenética de la horda primitiva que asesina y devora al padre [Totem y tabú] y que mantiene al ser humano entre la rebelión y la sumisión al padre dominante. Considerar en detalle el complejo de Edipo, su mayor o menor relevancia en la estructura psíquica y en el origen de la psicopatología, no será nuestro objeto de discusión aquí, compartiendo con Kohut (1977) su consideración del Edipo como una respuesta a las fallas de empatía del adulto, resultante de las fallas de narcisización en los hijos de padres narcisistas, que usan a los hijos para gratificar sus necesidades de ser admirados y deseados. Pero anticipando lo que los primeros investigadores del desarrollo aportan, no podemos dejar de lado las aportaciones de Lacan (1949) que subraya el pasaje de lo imaginario (diádico) a lo simbólico, donde la castración simbólica constituye la "ley del padre" o metáfora paterna, cuya instauración permite la ruptura de la unión madre-hijo, dando acceso al lenguaje y la subjetivación de la persona en la cultura.

La principal razón de no prestar ahora más atención a Freud es el hecho de que, aunque Freud formuló hipótesis metapsicológicas en torno a la función del padre en el desarrollo 
infantil y la estructura psíquica del adulto, no exploró la relación padre-hijo/a en ninguna de las primeras etapas evolutivas, apenas la edípica y post edípica, ni abordó específicamente el significado de la paternidad en la evolución del adulto. Esta laguna no será exclusiva de Freud, sino compartida con la mayoría de los desarrollos psicoanalíticos (M. Klein, W. Bion, D. Winnicott ${ }^{C}$ ), incluso los de los primeros investigadores del desarrollo (p.e. Mahler, 1955) que desplazan el interés hacia las etapas pre-edípicas, si bien es a partir de Margaret Mahler que el padre recibe un lugar destacable, aunque secundario, en el desarrollo infantil, por aparecer en la conciencia del niño/a desde el mundo exterior (externo a la simbiosis madrehijo/a), lo que le facilita ejercer un papel de apoyo al proceso de individuación/separación del niño/a respecto de la figura materna. Siendo así un representante del mundo externo, el padre es quien está mejor dispuesto para ofrecer al hijo/a una alternativa a tener que reinstalarse en una simbiosis regresiva con la madre (Mahler, 1971). De manera similar, aunque Bowlby (1988) verá al padre como un "protector" de la relación madre-niño, señalará también la necesidad de que intervenga creando su propia relación con el hijo/a potenciando su separación saludable de la madre.

Abelin (1975), continuador de Mahler, considerará al padre como el "representante del mundo no-materno", cuya función es abrir al hijo la perspectiva de un mundo de relaciones plural. El padre puede desempeñar ese papel, y en la medida en que gratifica las necesidades afectivo-emocionales de la madre, reduce la posibilidad de que la madre deposite la gratificación exclusiva de esas necesidades en el hijo/a, quien si se empapase de la ansiedad transmitida por la madre tendría muchas más dificultades para separarse de ella (Henderson, 1980). Sullivan ya subrayó esta asimilación de la ansiedad como desencadenante de la adaptación patológica del hijo/a a las necesidades de sus padres, neutralizando su ansiedad (Sullivan, 1959).

Junto a las vicisitudes del proceso de individuación/separación, está la formación de la identidad de género en el niño/a. Peter Blos (1984) consolida la comprensión psicoanalítica de que la formación de la identidad de género es muy anterior a la premisa de Freud de que esta tenía lugar durante la fase fálica en torno a la toma de conciencia del significado de las diferencias sexuales anatómicas. Blos, en relación con la adquisición de la identidad masculina en el niño, subraya como este reconoce y valida por especularización sus despliegues de las conductas de génerod. Aunque Blos se refiere al niño varón que se especulariza con el padre estableciendo su sentido básico de masculinidad, debemos entender que el proceso no excluye facetas similares (por especularización positiva o negativa) en la niña, que construye así un sentido subjetivo de lo que recibe aprobación por ser "masculino", y lo que es rechazado por ser "femenino". Puesto que el padre que especulariza al hijo o hija lo hace desde su particular construcción de su propia identidad de 
género, se abre un universo de posibilidades de identificación por afirmación y negación. Un rango que varía entre lo que Abelin describe como la "identidad de género segura" que emerge de las vivencias de la triada padre-madre-hijo, en la que el hijo organiza la representación de sí mismo en torno a la identificación con el deseo del padre hacia la madre, "ser él, como el padre, deseando a la madre" (1975) y las numerosas variantes de esta escena en la que el hijo o la hija se encontrarán ante un complejo mundo de anhelos y rechazos entre sus padres y de ellos hacia sus hijos.

Unido a su capacidad para ser el representante del mundo externo y sus aportes como figura de identificación para la constitución del self, el padre puede jugar un destacado papel como regulador emocional. Se ha subrayado el especial papel del padre en la modulación de los impulsos agresivos del niño/a (Fonagy y Target, 1997), y como la presencia vs. ausencia del padre resulta determinante en la aceptación de la demora en la gratificación / tolerancia a la frustración, especialmente si el padre se siente menos amenazado por los impulsos hostiles del niño/a, contribuyendo así a regularlos al tolerar una mayor expresión de los mismos, pero conteniéndolos y controlándolos. La hostilidad infantil recibe así menos respuestas reactivas, neutralizando parte de la carga hostil de las frustraciones de cuidado a través del vínculo con el padre que haría posible reconducir lo hostil a la exploración y al juego. Obviamente este papel no es privativo del padre, pero si la madre está más sobrecargada atendiendo a las necesidades básicas, el padre puede reconducir las frustraciones de las inevitables carencias, regulando al hijo/a y descargando a la madre, con su mirada desde el exterior del conflicto madre/hijo-a.

Estas propuestas, que asumen que el padre es un "objeto segundo" que aporta lo exterior ("el primer extraño", el "representante del Otro" u "Otro originario"), reposan sobre un sesgo cultural más propio de la sociedad occidental de base patriarcal: el padre es valorado y reconocido por sus capacidades de aportar desde el exterior los recursos que la familia necesita, mientras el mundo de los cuidados básicos, la provisión emocional y la organización de la vida familiar reposa en la madre. En nuestras sociedades abiertas a los nuevos modelos de familia, con roles diversos que no tienen porque coincidir con los de la familia tradicional (el padre puede ser el cuidador principal, y la madre la que provee desde fuera; o bien en las familias monoparentales que usan -o no- cuidadores externos; o en las familias donde hay dos madres o padres), estos nuevos paisajes familiares nos fuerzan a efectuar una reconsideración esencial de las funciones del padre y de la madre, y sus significados.

Aunque en mucho menor número, se han efectuado investigaciones centradas en la observación de la interacción temprana padre-bebé, en parte similares a las efectuadas 
sobre la interacción madre-bebé. Dorothy Burlingham (1973) publicó un extenso informe sobre interacciones padre-hijo/a en la etapa pre-edípica, extraído tanto de la literatura narrativa, de la clínica, y de propuestas teóricas, como de la observación directa y del análisis. A diferencia de los patrones de interacción maternos que tienden a ser suaves, generadores de confort y que van directos a la necesidad, la interacción paterna tiende a ser más activa, excitante, estimuladora, y por ello a veces causa malestar y ansiedad. En cambio, el bebé reacciona al cuidado materno como un receptor pasivo, mientras que ante el cuidador paterno es más probable que evoque reacciones activas en el hijo/a. Si los roles predominantes en la cultura cambian, y la madre despliega patrones paternos, mientras que el padre despliega patrones maternos, se produce una "parentalidad combinada" donde los roles se invierten, bien situacional o permanentemente.

Algunos años después de Burlingham, Yogman (1982) y Cath (1986) han documentado una interacción fluida entre padre y bebé a los seis meses de edad, incluyendo procesos de regulación y mutuo reconocimiento, con bebés de ambos sexos. Más allá de las interacciones tempranas, las investigaciones observacionales con niños confirman que hasta los diez años en el varón, la función paterna es clave para la adquisición de mayor autonomía, individuarse, separarse, y devenir en lo real -en la acción frente al refugio en la fantasía- más potente y creativo (Ross, 1977).

En estas tempranas etapas la calidad relacional consistente en cuidados, regulación y reconocimiento, son esenciales para la construcción de una imagen de sí y del otro bien integrada. Las fallas en el despliegue de esas funciones derivan en imágenes fragmentadas del padre y de sí mismo, bien idealizadas, devaluadas, o con distorsiones que se proyectarán en las relaciones que desplieguen el hijo o hija con ulteriores figuras relacionales, de un sexo y de otro, muy especialmente en la adolescencia y la etapa de joven adulto, donde se vivirán como "anhelo de padre" las fallas de presencia paterna cuando esta es necesaria y requerida para el proceso de diferenciación y construcción de su identidad (masculina y femenina), por identificación o como garante del acceso a la alteridad.

En el supuesto del hijo varón, que ha vivido una experiencia relacional con el padre idealizado, donde ha apoyado en dicha idealización la percepción de sus propias capacidades, este puede ser también sostenido en sus exploraciones agresivas por el padre real capaz de ser el contenedor de sus necesidades evolutivas, en una progresiva desidealización del padre -sin perder el vínculo- dando acceso a su propio ideal del Yo adulto. Cuando este hijo varón, ya joven adulto, afronte sus anhelos de paternidad, revivirá sus propias experiencias con su padre, mientras a su vez espera convertirse en padre. 


\section{Anhelando al padre}

Herzog (1982) realizó un estudio con 103 varones en espera de ser padres, en el que se puso de manifiesto que los futuros padres que se sentían en conexión con una figura paterna cálida en su niñez, eran más capaces de afrontar las vicisitudes de la paternidad, e implicarse emocionalmente con sus parejas durante el embarazo, mientras que los futuros padres marcados con el "anhelo de padre" de quien habían sentido su carencia en la infancia se mostraban mucho más ambivalentes ante el embarazo de sus parejas. Es decir, la expectativa de paternidad reactualiza las experiencias relacionales constitutivas con la figura paterna, volviendo a vivir esa conflictiva, y proyectándola en sus hijos/as como expectativa de ambivalencia que ellos revivirán más tarde con el nuevo padre.

Los ecos transgeneracionales de la lucha y sometimiento al padre dominante se reactivan ante la nueva experiencia de paternidad agente, donde puede darse además una notoria ruptura con los modelos arcaicos, des-identificándose del padre originario ${ }^{e}$, para poder asumir sin grave conflicto o con una mínima ambivalencia los retos de la parentalidad compartida. Cuando este proceso de cambio y puesta en ejercicio de las funciones parentales se da en un contexto de coexistencia de identificaciones primarias (repudiadas o no) con un padre patriarcal, junto a los nuevos valores adquiridos en la construcción de la representación de sí mismo en torno a los ideales sociales de progreso en un marco de igualdad y co-responsabilidad, las tensiones psíquicas están servidas, y requieren ser abordadas. La culpa, bien por ser punitivos o permisivos, acompaña la experiencia que muchos padres viven de la contradicción entre los valores que les han sido transmitidos, y aquellos con los que se ha identificado en su proceso de diferenciación. Un escenario donde la falta de límites y de control puede ser tan invalidante y caótico como los excesos de la represión autoritaria. Ante la pérdida del rol identitario tradicional, derivará bien en la escisión por la herida narcisista causada por no ser reconocido y aceptado como padreautoridad, expresada esta herida como rabia o cólera narcisista, bien en la desvitalización y desconexión que ocultará toda exploración y aventura posible orientada al crecimiento.

Se constata con frecuencia una "solución" problemática ante estas tensiones manifestada a través de la huida del compromiso que representa la paternidad (y la intimidad comprometida con la pareja), negándose a ser padre, resolviendo así en falso la angustia de ser y no ser como el padre autoritario y abusador, o la madre invasora de la intimidad y controladora, abrazando en cambio el limitado ideal de "nunca perder mi libertad" frente a la riqueza -incluida su conflictiva- que brindaría la experiencia de terceridad a la que le confrontarían los hijos. 
Ser padre es pues un ejercicio de terceridad donde se integra la identidad del padre, que contiene y metaboliza su propia rabia, regulando sus afectos negativos y positivos, así como la tolerancia de estos mismos procesos en sus hijos, que pueden así usar de nuevo la idealización, de forma más flexible y madura, en la integración de sus identidades singulares. Esta dialéctica de terceridades resulta en un sentido de pertenencia solidaria, que transciende las generaciones, y que se da en un escenario en el que se han superado las dicotomias rígidas de la familia patriarcal (o matriarcal).

Expresar, acompañar y contener las emociones que se viven como hijo/a de un padre, y como padre de un hijo/a es un elemento crucial para el desarrollo saludable posterior, bien del hijo/a que construye su identidad en el reconocimiento / diferenciación, bien del padre que se completa a sí mismo en la continuidad generacional. Kohut $(1977,1984)$ ha prestado especial atención a estos fenómenos al revisar el crucial papel que el padre tiene en la línea de desarrollo narcisista del hijo, como soporte de los ideales, a través de sus funciones como objeto del self, primero por especularización empática, después por idealización, y finalmente por gemelaridad. Si el padre (real y/o reconstruido en el análisis) ha cumplido aceptablemente esa función, su estela como objeto del self validador acompañará al hijo toda la vida.

Tanto para el hijo varón, como para la hija mujer, ese padre que portaba ese "anhelo de padre" si ha conseguido integrarlo en sus ideales, facilitará en el hijo/a la construcción de un ideal del Yo maduro, y la re-identificación con él cuando las crisis vitales cuestionen sus recursos y la coherencia e integridad de su representación de sí mismo. Kohut sostiene que ese "hambre de padre" que acompaña toda la vida al ser humano, fuente de vulnerabilidad psíquica, puede comprenderse mejor si no lo enfocamos como un derivado patológico de la represión o de la escisión defensiva frente a las fallas de la narcisización, sino como una parte universal del desarrollo normal, que contribuye a la evolución saludable del narcisismo, y sus ulteriores transformaciones. Obviamente no es lo mismo la familia estructurada triádica que "pierde" al padre, que la que deviene de una carencia originaria del mismo, y no puede usar imágenes ni positivas ni negativas como referentes. En las familias que devienen monoparentales, esa tensión de la falta requerirá ser elaborada resilientemente en nuevos escenarios que incluyan terceridad a través de la implicación con otros reales, aunque sea un camino de lenta y dolorosa transformación del padre faltante en un tercero simbólico integrado en las nuevas experiencias de relación con los otros que el ciclo vital puede deparar, un tercero simbólico integrado en el sí mismo que facilita a la persona la orientación al futuro y las opciones de transformación simbólica que toda relación madura exige. 
La importancia del ejercicio de la función paterna, en el marco de la parentalidad -es decir, compartida con la madre y/o integrada coherentemente con la función materna- no ha sido reconocida socialmente como tal hasta la crisis de la misma en el marco de la sociedad globalizada contemporánea, y solo cuando no cuestiona tradiciones religiosas o socioantropológicas atinentes a un contexto socio-cultural concreto. En las sociedades de tradición patriarcal, la función materna y la madre son colocadas en el centro del ejercicio de la parentalidad, mientras que, como ya se ha apuntado, el padre queda relegado al papel de provisor. Una consecuencia directa de esta asignación social de roles es que a la madre se le atribuya el papel causal de cualquier desviación o distorsión del desarrollo psíquico y adaptación social del niño o niña, mientras que el padre pasa a ser el objeto de reconocimiento de los logros que sus hijos tengan. Es decir: la madre "educa" y el padre "potencia", lo que constituye una "trampa cultural" que puede dificultar la pluralidad de funciones que ambos padres pueden compartir.

Con el aura de gratificación narcisista que para la madre pueda representar que sus hijos dependan de su amor y cuidados, la propia figura del padre puede pasar a ser un niño más que necesita cuidados, lo que supone una sobrecarga más en la alienación de la madre, que siempre habrá de estar dispuesta a "todo sacrificio" por el bien de los hijos. La madre, que frecuentemente dependerá económicamente de la actividad del marido, resulta así responsable -en su rol psicosocial- de sostenerlo todo, incluido el marido provisor, sin obtener reconocimiento por su titánica tarea en la que a pesar de estar desplegando máximas capacidades quedará sin embargo privada del soporte afectivo y social que necesita. Es la responsabilidad del ejercicio de la paternidad por parte de ambos, padre y madre, acabar con esta desigualdad lacerante.

Pero muchos padres desertan, o provocan inconscientemente su abandono del escenario familiar, como forma de escapar de sus cargas. Padres que apenas ven a los hijos "refugiándose" en las exigencias de su trabajo, y que justifican su ausencia no solo física sino también psíquica de la vida familiar. Una lucha entre la "realización personal" y las exigencias familiares, en las que la madre carece de derechos, y el padre encuentra justificación para negar su incapacidad de sostener y para efectuar la huida del compromiso contraído con su familia y con su contribución generativa a la sociedad. En la radical dialéctica entre "cuidarse a sí mismo" y "cuidar a los otros", el padre tiende a optar por si, mientras que la madre se relega en favor de los demás. Goldstein (1977) ya apuntó hace cuatro décadas los grandes temas de hoy para la mujer que opta por reinvindicarse plenamente, cuestionando la vigencia del ideal femenino de la maternidad, rechazando que no se sea una mujer completa si no se es madre, así como negarse a perpetuar el modelo de familia tradicional. Temas centrales para el despliegue y realización de la 
subjetividad de las personas, en el que la historia se ha inclinado muy mayoritariamente en favor del varón que "continua su proyecto", sean cuales sean las circunstancias que deja detrás. Ese papel que al padre le asigna el mostrar "qué debe hacerse, como y con quien", pero al que no se le pide que se haga cargo de las circunstancias del día a día de la parentalidad.

Reformulemos pues el tradicional "papel provisor" del padre, trascendiendo los roles sociales y funcionales, llevándolo a su esencial contribución como provisor de funciones de Objeto del Self. Toda persona que puede ser padre pertenece a un contexto cultural dado y a una realidad social, que se habrá ido transformando con él. Son muy diferentes los padres que viven ahora su momento como tales, de aquellos que lo fueron hace un siglo o varias décadas. Todos sin embargo han tenido (hemos tenido) que articular la forma en que la cultura y sociedad a la que se pertenece moldea la masculinidad y paternidad, con nuestra propia construcción del padre que queríamos ser, hayamos fallado o no en lograrlo.

Sobre el impacto social y cultural que una persona recibe moldeando su experiencia de lo que representa lo paterno y la paternidad ya hemos insistido en los anteriores apartados. Ahora, mediante el examen de las funciones psíquicas que caracterizan la función paterna, subrayaré cuales pueden ser las más importantes, y consideraremos como se configuran y despliegan.

Toda persona ha experienciado las características de la relación con su propio padre, o con las múltiples variantes de su presencia, ausencia o carencia. Las vicisitudes de quien resultó ser y las experiencias vividas con la figura paterna han ocupado un lugar central en la línea de desarrollo narcisista de cualquier adulto, especialmente en la configuración de los ideales.

El deseo de ser padre, y los anhelos depositados en el vinculo parental por el futuro padre, está fuertemente influido en una persona por la calidad de la relación que haya tenido ( $y$ mantenga) con el padre, así como por la disponibilidad emocional que este haya tenido ( $y$ tenga) con él ahora. El propio padre habrá suscitado una inevitable ambivalencia, que puede haber ido siendo resuelta en la cercanía del diálogo y la experiencia compartida, o puede haber quedado cristalizada en una relación "imposible", reiteradamente fallida. La literatura da frecuente noticia de la difícil -sino inviable- relación con el padre, frecuentemente relatado como "no disponible" para el vínculo con su hijo al que niega como ser diferente y/o trata cruel y despóticamente (p.e. Kafka y su Carta al padre; Dostoievsky y sus Hermanos Karamázov) o directamente como la causa de su imposibilidad de vivir por sí mismo, cerca del padre (p.e. Edmund Gosse: Padre e hijo). 
Se ha vivido pues la experiencia con el propio padre, tanto en los aspectos integrados como renegados, principalmente de su disponibilidad o no para el vínculo y acerca de su accesibilidad a la intimidad y al contacto emocional; también se ha sido testigo de otros padres posibles, observados en los vínculos de nuestros pares, o sobre todo, fantaseados. La sociedad habrá primado unos modelos sobre otros. Cada persona desde su experiencia del padre integrada en la identidad, junto al "anhelo de padre" que se necesita completar, oscila entre el uso del padre real vivido como objeto del self que mantiene la cohesión de nuestra potencial identidad como padre, y la búsqueda de objetos del self que restituyan al padre perdido.

La relación con el padre, y "ser padre" es un estado de crisis, y algo a (re)construir. Quizás todo padre en nuestra cultura occidental desde el último cuarto del siglo XX ha pasado o pasa por una tensa metamorfosis desde la figura del padre distante, "protector y provisor", al padre implicado y cercano, más emocional, capaz de sintonizar con las necesidades emocionales y de reconocimiento del hijo o hija, pero a la vez menos seguro y sólido. Sobre las funciones y vicisitudes de esta "parentalidad líquida" se han hecho contribuciones destacables que invito a revisar (Tizón, 2011, 2015, 2016).

Del mito del padre distante, todopoderoso y odiado, podemos haber pasado al padre amado y disponible para la conexión, pero frágil. Entre uno y otro extremo, el hijo necesita al padre como fuente de funciones de objeto del self, que brinden sostenimiento y contribuya a construir el sentido de sí mismo y la autoestima. Aunque en una primera aproximación pueda parecer lo contrario, es el padre cercano y disponible quien mejor puede contribuir a la construcción de un sentido positivo y cohesionado de sí mismo en el hijo, pues el padre cercano estará, muy probablemente, realmente interesado en conocer la subjetividad del hijo y contribuirá a su configuración. Si el padre real no ha estado disponible, probablemente se ha construido un "padre anhelado" que, aunque más deficientemente, funciona como un objeto del self imaginario, en el sentido que ya hemos descrito a partir de la obra de Herzog (2001). La pérdida del padre real, y el "anhelo de padre" sustitutivo, una especie de "padre anhelado interior" (un padre intrapsíquico) sumerge al adulto en una búsqueda de padre real desplazado a figuras sustitutivas en las que la persona (todavía niño o ya adulto) busca encontrar el correlato de la imagen idealizada del padre que necesitaron (y necesitan) (Jones, 2007; Dick, 2011).

La construcción de ese "padre interior" atraviesa las vicisitudes y contradicciones de la cultura y sociedad en la que la transformación de la figura del padre ocurre, una dinámica en la que la sensibilidad y capacidad de conexión emocional de ese "padre reparador posible" es crucial para la integración del self del adulto carente de padre, o intensamente 
ambivalente con él. El trabajo terapéutico dará una oportunidad de explorar ese vínculo, y de expresar y resignificar sus anhelos del padre que fue necesitado, sus fallas, también sus aportes particulares, por identificación positiva o negativa, haciendo posible que emerja un sentido del self más fuerte y propio, sin renegar de lo vivido, bien por haberlo tenido o haberlo perdido. Pero, como psicoanalistas, debemos estar atentos a nuestras propias maniobras inconscientes ante el impacto personal de esas fallas en nuestra historia personal. Rycroft $(1973,2010)$ hizo una trascendental contribución en la que describe los procesos carenciales que conducen a algunas personas, y en particular a los psicoanalistas, a realizar una "ablación" de sus figuras parentales si estas portan la huella de una interacción traumática y a desarrollar la ilusión narcisista omnipotente de haberse creado a sí mismos, lo que cierra o dificulta gravemente el camino a la terceridad en el trabajo con las personas que les necesitan como objetos transiccionales (paternos) para el acceso a la terceridad que exige la paternidad. Este es un reto central a elaborar en nuestros propios análisis.

\section{Hacia una paternidad generativa}

Afortunadamente, la sociedad actual ya no reserva al padre el exclusivo rol patriarcal del pasado, que si bien "blindaba" socialmente su rol, era a costa del sacrificio de sus más genuinas características humanas: la conexión emocional, el acceso a la intimidad, la mutualidad relacional, la terceridad. Por ello nos resulta más accesible reinterpretar el lugar del padre desde las aportaciones que una lectura relacional y desde la Psicología del Self podemos hacer del hombre como padre, y del hijo como futuro padre. Ya no necesitamos mantener a ese padre distante, física y emocionalmente, al que odiar y con el que rivalizar y superarle como marca de nuestra capacidad, sino que necesitamos un padre capaz de ser él mismo con el otro, un padre que brinda a su hijo/a con su presencia activa la generatividad de la relación real y también su disponibilidad como objeto del self actual y duradero.

Kohut (1977) clarificó esta función esencial para el desarrollo de la subjetividad, pues ambos padres contribuyen a la construcción de la autoestima y a la integración de la identidad del hijo/a, a través de sus respuestas empáticas a la conexión que viven con la subjetividad de sus hijos. Los hijos que crecen viviendo esta conexión empática, usan la especularización con su padre y madre, disponen de la idealización que les permite contruir su ideal del Yo maduro, y experiencian la gemelaridad que completa el desarrollo narcisista esencial, antes de que el propio sujeto lo trascienda en sus transformaciones adultas en el ciclo vital. La conexión necesaria para que estas funciones se desplieguen y contribuyan al desarrollo del 
hijo/a, es fundamentalmente conexión emocional, con resonancia empática, en la que el sujeto se siente comprendido, no solo intelectual o instrumentalmente, aunque lo racional pueda facilitar la estructura necesaria si la base de la conexión prima lo emocional sobre la razón. Comprender y aprender a funcionar en el mundo (relacional) se adquiere mucho más plenamente si la persona se siente entendida y reconocida en sus vivencias, lo que se une a la experiencia de sí como parte esencial, y permite que se avance en ser uno mismo apoyado en el otro con el que nos identificamos, y del que nos diferenciamos.

No es un único patrón de paternidad el que resulta deseable, sino quizás la variedad de posibilidades que ofrezca el padre en su relación con el hijo, lo que enriquece los recursos de este para lograr un sentido más pleno e integrado de sí, y una autoestima más rica y flexible. Como pusieron de manifiesto Dick y Bronson (2005) los hombres con una mayor autoestima informaban que sentían a sus padres más implicados con ellos, así como emocionalmente disponibles, cariñosos, comprensivos, dando ánimos, confortando y expresando sus afectos. Es decir, los percibían significativamente más accesibles y protectores que los hombres con baja autoestima. Estos hombres habían recibido feedback especular (sentirse admirados, afirmados, aceptados y reconocidos por un padre cariñoso, expresivo emocionalmente). Habían desarrollado la idealización del padre (y de otros adultos) como un sentido de respeto y admiración, sin sacrificar la crítica que acepta lo real (admirables, pero no perfectos, aceptando progresivamente sus fallas); finalmente, y quizás especialmente, habían vivido la experiencia de la gemelaridad, donde la relación con el otro semejante es posible y satisfactoria, siendo como el otro (pero no idénticamente). Sobre la base de sus propias experiencias con el padre (real o reconstituido), el varón puede acceder a una vivencia más plena y activa de su propia identidad y paternidad.

Como ya hemos descrito, la falla paterna (bien porque haya fallecido, sea éste desconocido, haya abandonado al hijo/a, por causas forzosas, o simplemente que esté presente en el hogar, pero no disponible), sea esta falla por ausencia real o por presencia desconectada del hijo, impedirá o dificultará gravemente el despliegue de las funciones descritas, que serán sustituidas por una experiencia de pérdida o carencia, o por una construcción imaginaria de "anhelo de padre", que no puede ser expresada a su destinatario real, que solo encontrará objetos sustitutorios inadecuados o disfuncionales, solo excepcionalmente adecuados y disponibles. Si esta "falla paterna" se manifiesta además a través del abuso psíquico o físico, la huella de la invalidación paterna, de ser humillado y avergonzado por el padre, resultará en una pérdida traumática de las funciones que hubieran sido necesarias para la construcción de la autoestima en el hijo, y dejará huellas duraderas que solo podrán ser restauradas parcialmente en relaciones de afirmación y validación de las que el hijo/a 
pueda disponer posteriormente, incluida la experiencia no retraumatizadora que puede vivir en el tratamiento psicológico. La huella de una ausencia, carencia o sufrimiento por abusos y maltrato no es compensada por la relación positiva y estructurante que pueda brindar la figura materna, habrá siempre de ser trabajada en cuanto tal.

Además de en nuestra práctica clínica, en la literatura encontraremos abundantes testimonios que complementan lo que la práctica nos trae. Es una lista ingente de aportaciones que no la podemos abordar aquí, aunque mencionaré algunos ejemplos destacados, además de los clásicos que ya he citado. Es especialmente rica la contribución de Arthur Miller en La muerte de un viajante (1949), donde se muestran muy claramente las vicisitudes del narcisismo entre padre e hijo. El clínico encontrará en la literatura contemporánea obras como Patrimonio: Una historia verdadera, de Philip Roth (1991), o la castellana Ordesa, de Manuel Vilas (2018), entre un sinfín de títulos relevantes.

\section{Trabajando la paternidad en la psicoterapia}

Desde la perspectiva relacional, y con los aportes de la psicología del self, el terapeuta dispone de un marco de intercambio y elaboración en el trabajo psicoterapéutico cuyas características centrales son la participación implicada que favorece la experiencia de la terceridad mediante la mutualidad éticamente asimétrica, la conexión empática que permite la sintonía emocional entre ambos partícipes, y la interpretación de los significados de las experiencias que se viven en el encuentro terapéutico, cargado de afectos, pero también de representaciones.

El psicoterapeuta varón -y complementariamente la psicoterapeuta mujer- despliega su sensibilidad para acoger, escuchar activamente, validar y afirmar la experiencia vivida por las personas que han vivido en la carencia, distorsión o abuso con padres ausentes o emocionalmente distantes. En la experiencia que la persona puede ahora vivir con su terapeuta se re-encuentra con las facetas de lo traumático, pero también con las oportunidades de reconstrucción a través de su función transiccional, de ser usado como objeto del self con el que primero tomar conciencia y reconstruir la experiencia de las fallas, y más tarde reconstruir las facetas del self dañado. No es una tarea fácil, porque los varones adultos que piden ayuda no suelen hacerlo porque tengan una percepción de sus dificultades y sufrimientos en la relación tenida o carente con su padre, sino que se manifiestan a través de una variedad de síntomas psíquicos (p.e. angustia, tristeza, obsesiones) y somáticos (desde el síntoma somático hasta la interpretación hipocondriaca), integrados en una atmósfera de desvitalización y difusión de identidad, desplazándose como naves sin rumbo. Es en la experiencia terapéutica donde va a tener 
lugar una "segunda" oportunidad para reconstruirse en un vínculo parental, tras una historia de vida marcada por ese "anhelo de padre" que le ha llevado a implicarse en relaciones donde podía fantasear que recibiría el feedback paterno faltante, pero que con frecuencia han sido re-traumatizadoras.

El terapeuta varón podrá así ser contingente a las necesidades de especularización, idealización y gemelaridad del varón adulto, ofreciendo un "segundo" objeto del self paterno, y también, aunque con otros matices, para la mujer adulta, en la que suelen coincidir sus experiencias con los aspectos fallidos de su padre y los desencuentros retraumatizadores de la experiencia que viven con el varón que es o puede ser el padre de sus hijos. La terapeuta mujer podrá desempeñar un papel esencial de "dar acceso al padre" en la experiencia de la relación terapéutica, contribuyendo a poner en marcha estos procesos de reconstrucción, tanto en varones como mujeres, con una "madre" que incluye al padre y reconstruye su importancia, tanto en sus fallas como en sus aportes. Complementariamente, Neil Altman (2008) nos ha aportado una clara visión que apoya el positivo papel que el terapeuta varón (y eventual padre de hijas) puede tener en la psicoterapia de las chicas adolescentes, desconfirmando la supuesta necesidad de que sus terapeutas sean mujeres, no repitiendo así, ni ahondando la tradicional retirada emocional del padre-varón, cuando la hija llega a la adolescencia.

El terapeuta varón, con el adulto varón, encontrará frecuentemente dificultades para sostener la experiencia de intimidad con una persona que, por sus carencias y distorsiones en la identificación masculina con un padre ausente, fallido o invalidador, revivirá o traducirá en el vínculo con el terapeuta una variedad de manifestaciones de "pánico homosexual". Con el terapeuta varón abierto a ser usado como objeto del self en la reconstrucción de su identidad, el varón joven o adulto experienciará vivencias de intimidad y sintonía emocional que le son desconocidas en la relación con otro varón, y que ahora le desconciertan y perturban profundamente pues nunca han dispuesto de un padre afectuoso disponible para la sintonía emocional con el. Algunos varones han podido disponer de un "compañero" del mismo sexo en la adolescencia ${ }^{f}$ con el que han vivido una intensa intimidad, que ha cubierto total o parcialmente esas necesidades de identificación masculina con una figura emocionalmente responsiva, lo que les ha brindado cualidades que pueden usar en su despliegue adulto. Pero otros no han dispuesto de esa riqueza relacional con los pares, y se han encaminado en la búsqueda de padres sustitutos, habitualmente fallidos, más pronto o más tarde, pues la esperanza de "encontrar" el padre anhelado resulta mucho más retraumatizadora cuando este le falla más tarde en su disponibilidad real, cuando no deriva en un mero uso del "nuevo hijo que anhela padre" 
poniéndolo al servicio de gratificar sus propias necesidades narcisistas, siendo así un "pseudo-padre" que ni es, ni merece ser.

Las fallas de conexión empática son inevitables en la crianza, desarrollo y vicisitudes de las relaciones con las figuras parentales y los compañeros y compañeras de vida. No son las fallas lo que es traumático en sí, sino la grave dificultad o imposibilidad de la reconexión, de la reparación de los vínculos en los que se sostiene la cohesión de la identidad del joven y del adulto. Padre y madre, hermanos y hermanas, compañeros y compañeras adolescentes, profesores, otras figuras de la familia extensa o padres y madres de amigos y compañeros pueden jugar papeles terapéuticos en la medida en que faciliten los procesos de reparación y desconexión con las figuras referentes esenciales para cada persona en el desarrollo de su identidad. Desdramatizando las pérdidas, carencias y distorsiones, el adolescente, joven y adulto necesita experiencias de especularización positiva que le permitan construir su identidad a la par que se siente aceptado, reconocido, y puede desarrollar procesos de idealización bidireccionales, en los que siente admiración por el padre / adulto y a la vez se siente admirado por él. Esto vendrá seguido en el desarrollo normal de su identidad, cohesionando su narcisismo saludable, como un recorrido en gemelaridad, donde se experiencia el estar con y vivir acompañado, en un contexto de mutuo reconocimiento de vivencias y capacidades. Un proceso a vivir en las relaciones que la persona tiene en su vida, y en particular en la relación que deviene terapéutica porque brinda estas calidades de experiencias, antes faltantes o inconsistentes.

¿Cómo facilitar a la persona la toma de contacto con las experiencias vividas con su padre? El psicoterapeuta con experiencia descubre, en su recorrido con el paciente, los momentos de acceso a este material, y las facetas a explorar. Desde nuestra tradición interpersonal usamos la riqueza que nos aporta la estrategia de la indagación detallada, que asume que no podemos renunciar a formular ciertas preguntas ${ }^{g}$, bien explícita o indirectamente formuladas, las cuales hemos de tener disponibles en nuestro acercamiento a cualquier paciente, varón o mujer, formulándolas cuando sentimos que es el momento adecuado:

Hábleme sobre su padre, ¿Cómo era? ¿Qué le llamaba la atención de él?

¿Cómo era la relación con su padre?

Comparta conmigo alguna experiencia memorable vivida con él.

Comparta conmigo algún momento de fracaso, ridículo, en el que haya sentido vergüenza en usted y de/con su padre

¿Estaba su padre emocionalmente disponible para vd? ¿Podía acudir a contarle un problema o dificultad? ¿Se sentía escuchado? 
¿Le dijo su padre a vd. que le quería?

¿Cómo se sentía estando vd. en presencia de su padre?

¿Se sentía aceptado por él? ¿Se sentía valorado por el?

¿Sentía que su padre le comprendía?

¿Qué hubiera necesitado de él, que no le dio?

Los psicoterapeutas tenemos, además, una especial responsabilidad en promover que nuestros pacientes que ya son padres, o que aspiran a serlo ${ }^{h}$, hagan de la experiencia de la paternidad una prioridad existencial a través de su plena participación en la misma, implicándose para que su parentalidad sea a la vez una experiencia de trascendencia generativa y de mutualidad con la pareja, lo que es clave para que la familia tenga existencia como contenedor emocional y espacio de crecimiento compartido. En el marco de la parentalidad, el self en desarrollo de cada integrante no puede ser la principal prioridad terapéutica, sino los avances en la terceridad logrados en el ejercicio compartido de la parentalidad.

El "nacimiento del padre", para cada nueva ocasión de ser padre, no es el mero hecho biosocial de tener un hijo, sino un conjunto de cambios psíquicos y de disponibilidad emocional. Esencialmente, la aceptación madura del lugar del sujeto en lo social-relacional (en sus límites y posibilidades)i; la (re) activación del "padre interno"j; y la disponibilidad para ser una figura significativa para el hijo/a, a lo largo del ciclo vital.

Estos cambios se apoyan en una construcción relacional derivada de la propia experiencia vivida en la matriz relacional en la que se ha sido hijo, en la que se ha convivido con padres reales, simbólicos e imaginarios, y en la que se ha construido una fantasía identificatoria, derivada de los diferentes padres posibles que se pueden ser, integrando ambiciones e ideales propios.

Podemos advenir a la paternidad siendo muy diferentes clases de padres: negados, narcisistas, maternales, generativos...

El padre negado, que se inhabilita para ser padre en lo real, habitando p.e. la fantasía del auto-engendramiento o evitando la confrontación dolorosa con el padre que no se tuvo.

O el padre narcisista que busca el objeto para su gratificación narcisista en el hijo/a, y lo subyuga. También el padre maternal que realiza sus fantasías de "ser una buena madre", desplegando su mater-paternidad. 
Finalmente, el padre capaz de serlo, con identidad madura, un padre generativo, que no invade el espacio de la maternidad, pero lo sostenie, y a la vez afronta la transformación de sus necesidades narcisistas en creatividad, aceptación de los límites y uso de la sabiduría.

Para acometer esta tarea del "nacimiento del padre" usamos capacidades de "materno/paterno-parentalidad" que se han construido sobre la base de la experiencia vivida directamente como hijo y nieto con los propios padres y abuelos; la experiencia vivida siendo testigos y partícipes de la relación de los padres con sus padres; y finalmente, de la transmisión transgeneracional que todos ellos portan y nos legan, sobre el sentido de la paternidad. La perspectiva relacional nos da una oportunidad de pensar estar matriz relacional en la que la paternidad se teje, disfuncional o saludablemente, donde quedan abiertos los numerosos interrogantes que surgen en torno a las numerosas variantes posibles en esta compleja experiencia que es la paternidad. Una tarea infinita, porque la experiencia de la paternidad (y maternidad) no termina nunca, troquela nuestra identidad, sean cuales sean las vicisitudes de lo real.

Concluiré con unos versos del poeta portugués Jorge de Senak, pertenecientes al poema "Te ha nacido un hijo":

$$
\begin{aligned}
& \text { Nasceu-te um filho. Não conhecerás, } \\
& \text { jamais, a extrema solidão da vida. }
\end{aligned}
$$

Se a não chegaste a conhecer, se a vida

ta não mostrou - já não conhecerás'

Lo que Sena nos transmite en estos versos es el radical cambio que la paternidad trae consigo, aboliendo el imaginario de la soledad. Se es padre siempre, aunque el hijo/a no esté. Ya no seremos los mismos ni con él/ella, ni sin él/ella. La paternidad inaugura un espacio psíquico que no tiene fin, como sucede con la relación terapéutica. Ambos, padre y psicoterapeuta han de aceptar la partida del hijo o del paciente, pues habremos de seguir estando disponibles en lo posible, aunque nunca más se nos requiera en ese lugar. Una huella que es bidireccional, pues como Stefan Zweig señala: "En la vida de todo hombre irremisiblemente llega el momento en que éste reencuentra la imagen de su padre en la suya propia" (Stefan Zweig, 2002, p. 26).

\section{REFERENCIASm}

Abelin, E.L. (1971). The role of the father in the separation-individuation process In J. B. McDevitt and C. F. Settlage (eds.), Separation-Individuation: Essays in Honor of Margaret S. Mahler New York: Int. Univ. Press. 
Abelin, E.L. (1975) Some Further Observations and Comments on the Earliest Role of the Father. Int. J. Psycho-Anal., 56:293-302.

Abraham, K. (1922). Rescue and Murder of the Father in Neurotic Phantasies. Int. J. Psycho-Anal., 3:467-474 Adatto, C.P. (1987). Son and Father. Before and Beyond the Oedipus Complex. Psychoanal. Q., 56:564-567.

Altman, N. (2008). From fathering daughters to doddering father. Psychoanalytic Inquiry, 28, 92:105

Blos, P. (1974). The genealogy of the ego ideal Psychoanal. Study Child 29, 43-88

Blos, P. (1984). Son and Father. J. Amer. Psychoanal. Assn., 32:301-324.

Blos, P. (1985). Son and Father. Before and Beyond the Oedipus Complex. New York: The Free Press. 186 pp.

Blos, P. (1987) Freud and the Father Complex. Psychoanal. St. Child, 42:425-441.

Bowlby, J. (1988). A Secure base. Clinical applications of Attachment Theory. London: Routledge.

Burlingham, D. (1973). The Preoedipal Infant-Father Relationship. Psychoanal. St. Child, 28:23-47.

Cath, S. (1986). Fathering from infancy to old age: A selective overview of recent psychoanalytic contributions. Psychoanalytic Review, 73, 469-479

Cook, J.L. Jones, R.M. Dick, A.J. Singh, A. (2005). Revisiting men's role in father involvement: The importance of personal expectations. Fathering: A Journal of Theory, Research, \& Practice about Men as Fathers 3:2165-178

Demby, S. (1990). The role of the father in the son's pre-oedipal development. Issues on Ego Psychology, 13, $147-156$.

Deutscher, M. (1981). Identity Transformations in the Course of Expectant Fatherhood. Contemp. Psychoanal., 17:158-170

Diamond, M.J. (1986). Becoming a father: A psychoanalytic perspective on the forgotten parent. Psychoanalytic Review, 73, 445-468.

Dick, G.L. (2011). The Changing Role of Fatherhood: The Father as a Provider of Selfobject Functions. Psychoanal. Soc. Work, 18(2):107-125.

Freeman , T. (2008). Psychoanalytic concepts of fatherhood: Patriarchal paradoxes and the pressure of an absent authority Studies in Sexuality and Gender 9:113-139

Freud, S. (1961a). Analysis of a phobia in five-year-old boy. In J. Strachey (Ed. and Trans.), The standard edition of the complete psychological works of Sigmund Freud (Vol. 10, pp. 1-149). London: Hogarth Press. (Original de 1909)

Freud, S. (1961b). Female sexuality. In J. Strachey (Ed. and Trans.), The standard edition of the complete psychological works of Sigmund Freud (Vol. 21, pp. 221-243). London: Hogarth Press. (Original de 1931)

Freud, S. (1961c). Interpretation of dreams. In J. Strachey (Ed. and Trans.), The standard edition of the complete psychological works of Sigmund Freud (Vol. 4-5 Entire Volume). London: Hogarth Press. (Original de 1900)

Freud, S. (1961d). Moses and monotheism. In J. Strachey (Ed. and Trans.), The standard edition of the complete psychological works of Sigmund Freud (Vol. 23, pp. 1-137). London: Hogarth Press. (Original de 1939)

Freud, S. (1961e). The question of lay analysis: Conversations with an impartial observer. In J. Strachey (Ed. and Trans.), The standard edition of the completepsychological works of Sigmund Freud (Vol. 20, pp. 179250). London: Hogarth Press. (Original de 1926) 
Freud, S. (1961f). Totem and taboo. In J. Strachey (Ed. and Trans.), The standard edition of the complete psychological works of Sigmund Freud (Vol. 13, pp. 1-162). London: Hogarth Press. (Original de 1913)

Goldstein, M.Z. (1977). Fathering-a Neglected Activity. Am. J. Psychoanal., 37(4):325-336.

Gurwitt, A.R. (1976). Aspects of Prospective Fatherhood-A Case Report. Psychoanal. St. Child, 31: 237-271.

Harris, A. (2008). "Fathers" and "Daughters". Psychoanal. Inq., 28(1):39-59

Henderson, J. (1980). On fathering (the nature and function of the father role). Canadian Journal of Psychiatry, 25, 413-431.

Herzog, J. (1982). Patterns of expectant fatherhood: A study of the fathers of a group of premature infants. In S. Cath, A. Gurwitt y J.M. Ross (Eds.) In father and child: Developmental and clinical perspectives (pp. 301-314). Boston: Little, Brown.

Herzog, J.M. (2001). Father Hunger: Explorations with Adults and Children, Hillsdale, N.J: The Analytic Press.

Hurn, H. (1969). Synergic Relations Between the Processes of Fatherhood and Psychoanalysis. J. Amer. Psychoanal. Assn., 17:437-451

Jones, A.K. (2007). Assessing the impact of father-absence from a psychoanalytic perspective Psychoanalytic Social Work 14:143-58

Josephs, L. (2007). Primal Fatherhood and Primal Rage. Am. J. Psychoanal., 67(2):150-161

Kohut, H. (1977). El Complejo de Edipo y la Psicología del Sí mismo. En La restauración del sí-mismo. Barcelona-Buenos Aires: Paidós, 1980. [Original de 1977]

Kohut, H. (1979). The two analyses of Mr. Z. International Journal of Psychoanalysis, 60 (1), 3-27.

Kohut, H. (1980). Summarizing reflections. In A. Goldberg (Ed.), Advances in self psychology (pp. 473-554). New York: International Universities Press.

Kohut, H. (1984). How does analysis cure? In Chicago: University of Chicago Press.

Lacan, J. (1949). Le stade du miroir comme formateur de la fonction du je telle que' elle Nous est revelee dans l'excperience psychoanalytique. En Ecrits, Paris: du Seuil, 1966 [pp, 93-100]

Lamb, M.E. (1996). The role of the father in child development 3rd ed. ed. et al.New York, NY: Wiley

LaRossa, R. (1988). Fatherhood and social change Family Relations 37:4451-457

Liebman, S.J. y Abell, S. C. (2000). The Forgotten Parent No More: A Psychoanalytic Reconsideration of Fatherhood. Psychoanalytic Psychology, 17:1 88-105

Mahler, M. S. (1971). A study of the separation-individuation process: And its possible application to borderline phenomena in the psychoanalytic situation. Psychoanalytic Study of the Child, 403-424.

Mahler, M., Pine, F. Y Bergman, A. (1975). The Psychological Birth of the Human Infant, New YorK. Basic Books.

Miller, A. (1949). La muerte de un viajante, edición y traducción de. Ramón Espejo Romero, Madrid, Cátedra, 2010 [Original de 1949]

Miller, T. (2010). "It's a triangle that is difficult to square": Men's intentions and practices around caring, work, and first-time fatherhood Fathering 8:3362-378

Minsky, R. (2000) Beyond nurture: Finding the words for male identity Psychoanalytic Studies 2:3241-253

Olmstead, S.B. Futris, T.G. Pasley, K. (2009) An exploration of married and divorced, nonresident men's perceptions and organization of their father role identityFathering 7:3249-268 
Osherson, S. (1986) Finding our fathers ed. et al.Chicago, IL: Contemporary

Panel (1978). The role of the father in the preoedipal years. R. C. Prall, reporter J. Am. qPsychoanal. Assoc. $26143-161$

Ross, J. (1975). The development of paternal identity: a critical review of the literature on nurturance and generativity in boys J. Am. Psychoanal. Assoc. 23 783-817

Ross, J.M. (1977). Towards Fatherhood: The Epigenesis of Paternal Identity During a Boy's First Decade. Int. R. Psycho-Anal., 4:327-347.

Ross, J. M. (1979). Fathering: a review of some psychoanalytic contributions on paternity Int. J. Psychoanal. $60317-327$

Ross, J.M. (1991). The darker side of the fatherhood: Clinical and Developmental ramification of the Laius Complex. En P. Hartocollis e I.D. Graham (Eds.), The personal myth in psychoanalytic theory (pp.257-277). Madison, CT: International Universities Press.

Roth, P. (1991). Patrimonio. Una historia verdadera, Barcelona: Seix Barral, 2011.

Rycroft, C. (2010). Sobre la ablación de las imágenes parentales o la ilusión de haberse creado a Sí mismo. Clínica e Investigación Relacional, 4 (1): 33-45. [Original de 1973]

Sarkadi , A. Kristiansson, R. Oberklaid, F. Bremberg, S. (2008). Father involvement and children's developmental outcomes: A systemic review of longitudinal studies Acta Paediatricia 97:153-158

Spieler, S. (1984). Preoedipal girls need fathers. Psychoanalytic Review, 71, 63-80.

Stoller, R.J. (1965). The sense of maleness. Psychoanalytic Quarterly, 34, 207-218.

Sullivan, H.S. (1959). La teoría interpersonal de la Psiquiatría, Buenos Aires: Psique. [Original de 1953]

Tizon, J. (2011). Funciones psicosociales de la familia y cuidados tempranos de la infancia. Temas de Psicoanálisis, 1 (Enero 2011).

Tizón, J. (2015). Crisis social y "Parentalidad líquida": Problemas y oportunidades. Parte I - Situándonos en perspectiva. Temas de Psicoanálisis, 10 (Julio 2015).

Tizón, J. (2016). Crisis social y "Parentalidad líquida": Problemas y oportunidades. Parte II - La necesidad de cambios téoricos, técnicos y prácticos en Psicoanálisis y Psicología del Desarrollo. Temas de Psicoanálisis, 11 (Enero 2016).

Target, M. \& Fonagy, P. (2002). Fathers in modern psychoanalysis and in society: The role of the Father in child development. In The importance of Fathers: A Psychoanalytic Re-evaluation, ed. J. Trowell \& A. Etchegoyen. New York: Taylor \& Francis (pp. 45-66).

Trowell, J. \& Etchegoyen, A. (2002). The importance of Fathers: A Psychoanalytic Re-evaluation New York: Taylor \& Francis

Vilas, M. (2018). Ordesa. Alfaguara.

VV. AA. (1999). Número monografico sulla funzione paterna. Psicoterapia Psicoanalitica. VI:2, 11-175.

Wall, G. Arnold, S. (2007). How involved is involved fathering? An exploration of the contemporary culture of fatherhood. Gender and Society 21:4508-527

Weisman, S.K. (2002). When Fathering Falls Short: A Review of Father Hunger: Explorations with Adults and Children by James M. Herzog. Hillsdale, N.J: The Analytic Press, 2001. 324 pp.. Contemp. Psychoanal., 38(3):554-559. 
Yogman, M.W. (1982). Observations on the father-infant relationship. En S. Cath, A. Gurwitt y J.M. Ross (Eds.) In father and child: Developmental and clinical perspectives (pp. 101-122). Boston: Little, Brown.

Zweig, S. (2002). El mundo de ayer. Memorias de un europeo. Barcelona: El Acantilado [Original de 1976]

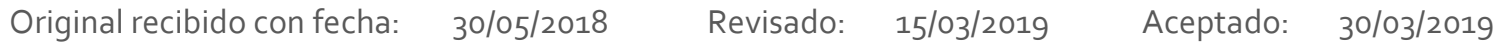

NOTAS:

a Alejandro Ávila Espada, Ph.D., Psicólogo Clínico. Catedrático de Personalidad, Evaluación y Tratamientos Psicológicos, Universidad Complutense (y anteriormente en la Universidad de Salamanca) desde 1990. Presidente de Honor del Instituto de Psicoterapia Relacional (Madrid), y miembro de la International Association of Psychoanalytic Self Psychology (IAPSP). Miembro de Honor de la Federación Española de Asociaciones de Psicoterapeutas (FEAP) de la que fue primer presidente. Miembro del Board of Directors de la International Association for Relational Psychoanalysis and Psychotherapy (IARPP) en el periodo 2011-2018. Editor de la Revista electrónica Clínica e Investigación Relacional. Entre sus obras: Manual de Técnicas de Psicoterapia. Un enfoque psicoanalítico (Madrid: Siglo XXI, 1994); Investigación en Psicoterapia. La contribución psicoanalítica (Barcelona: Paidos, 1998), ambos con J. Poch; Introducción a los tratamientos psicodinámicos (con B. Rojí y L.A. Saul; Madrid: UNED, 2004); La tradición interpersonal. Perspectiva social y cultural del psicoanálisis (Madrid: Ágora Relacional, 2013) y de Relational Horizons: Mediterranean voices bring passion and reason to relational psychoanalysis (Astoria, NY: International Psychoanalytic Books, 2018). Asesora en calidad de Director Clínico a la entidad Ágora Relacional, dedicada a la atención clínica y la formación continua en salud mental. Más información actualizada y una selección de sus publicaciones con opción a descarga puede encontrarse en: http://www.psicoterapiarelacional.es/paginaspersonales/AlejandroAvilaEspada.aspx

${ }^{\mathrm{b}}$ En la conceptualización freudiana de la resolución del Complejo de Edipo, el rol patriarcal del padre le brinda al hijo varón oportunidades de identificación, quien es más proclive a la idealización del padre, con quien puede identificarse y construir un sentido de aceptación de los límites que impone la cultura. En la hija mujer ese proceso es menos evidente, pues la hija tiene -en la cultura- menos que ganar con la identificación con el padre. Pero la hija/mujer actual ya no asume el papel social asignado a la mujer en la época de Freud, y en consecuencia las perspectivas de su evolución identitaria son muy diferentes.

c Winnicott no le da al padre un papel singular, y como Klein carece de propuestas sobre su función como figura alternativa de identificación o de apoyo a la madre. Winnicott y M. Klein despliegan modelos "centrados en la madre".

d Blos subraya que el papel de la relación diádica temprana del padre con el hijo ha sido infraestimada. Una relación idealizada, que no es solo necesaria para el reconocimiento y aprobación, sino también como un "protector" que refuerza su confianza en lograr autonomía, y resistencia frente a los tironeos de la madre simbiótica infantilizante y regresiva. Una relación precoz en la que el chico varón se siente protegido y querido por el padre, que llegará a ser internalizada como un sentido de seguridad en si mismo que le acompaña toda la vida (Blos, 1984).

e Se reactiva la identificación con el padre originario que había sido repudiada en el Ideal del Yo adulto.

${ }^{f}$ H.S. Sullivan hizo un énfasis especial en la relevancia de los procesos que se viven con ese "compañero" del mismo sexo, en la adolescencia.

9 Las preguntas escogidas se inspiran en la propuesta de Dick (2011) y en la propia experiencia de trabajo psicoterapéutico en la clínica.

h Para el varón hay también un "tiempo" de preparación para la experiencia de la nueva paternidad, en que se puede primar el trabajo de las fantasías (y del fantasma), al carecer el padre de la relación corporeizada que la madre tiene con el hijo/a durante el embarazo. En el caso de las adopciones, los tiempos cambian, y pueden ambos padres perder la posibilidad de prepararse psíquicamente, trasladando ese trabajo a la experiencia posterior que ya se vivirá directamente con el hijo/a adoptivo.

@ Derechos reservados/Copyright de Clínica e investigación Relacional y los autores. Prohibida la reproducción total o parcial sin autorización expresa. Este material es para uso científico y profesional exclusivamente y puede contener información clínica sensible. Los editores no se responsabilizan de los contenidos de los autores. Dirigir las consultas sobre derechos y autorizaciones a ceir@psicoterapiarelacional.es 
' Lo que en términos más clásicos sería denominado su función como organizador de la vida psíquica a través del Complejo de Edipo (Freud) o Ley del padre (Lacan).

${ }^{\mathrm{j}}$ Resultante de la matriz relacional vivida.

${ }^{k}$ Nacido en Lisboa (1919) Fallece en Santa Bárbara, California (1978). Los versos que se incluyen fueron publicados dentro de la compilación póstuma "Visión perpétua" Visão Perpétua (1982). Agradezco a Gonçalo Neves su ayuda, que me ha permitido tomar contacto con la obra de este poeta.

' Te nació un hijo. No conocerás, / jamás, la extrema soledad de la vida. / Si no la llegaste a conocer, si la vida / no te la mostró - ya no la conocerás

$\mathrm{m}$ Véase también para una variedad de aportaciones la Revista: Fathering A Journal of Theory Research and Practice about Men as Fathers (EBSCO Publishing) 